Portland State University

PDXScholar

$3-5-2020$

\title{
Impact of the Urban Heat Mosaic on the Leaf Senescence in Two Acer Species
}

Jeffrey D. Smith

Portland State University

Follow this and additional works at: https://pdxscholar.library.pdx.edu/honorstheses

Part of the Biology Commons, and the Plant Biology Commons Let us know how access to this document benefits you.

\section{Recommended Citation}

Smith, Jeffrey D., "Impact of the Urban Heat Mosaic on the Leaf Senescence in Two Acer Species" (2020). University Honors Theses. Paper 833.

https://doi.org/10.15760/honors.852

This Thesis is brought to you for free and open access. It has been accepted for inclusion in University Honors Theses by an authorized administrator of PDXScholar. Please contact us if we can make this document more accessible: pdxscholar@pdx.edu. 


\section{Impact of the Urban Heat Mosaic on the Leaf Senescence in Two Acer Species}

by

Jeffrey Smith

An undergraduate thesis submitted in partial fulfillment of the requirements for the degree of a

Bachelor of
Science

in

University

Honors

and

Biology

Thesis

Advisor

Olyssa Starry, PhD

Portland State

University 


\section{Table of Contents}

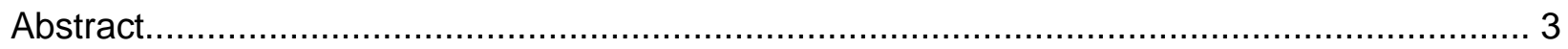

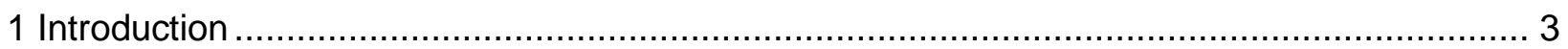

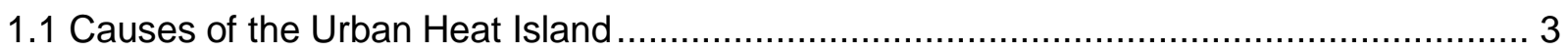

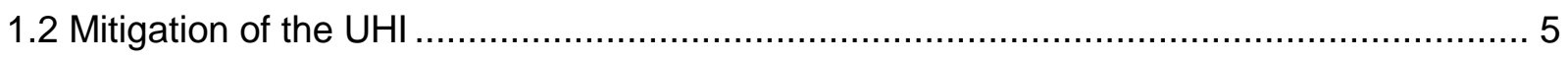

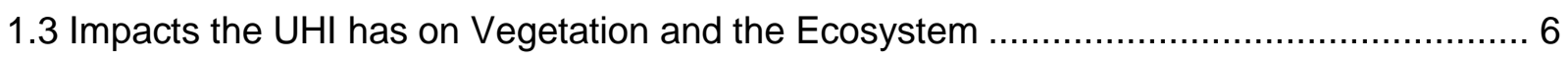

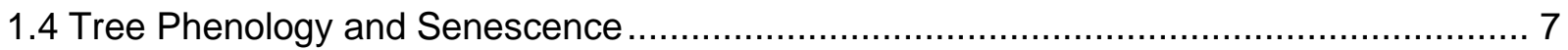

1.5 A Response to the Declining Health of the Urban Ecosystem......................................... 8

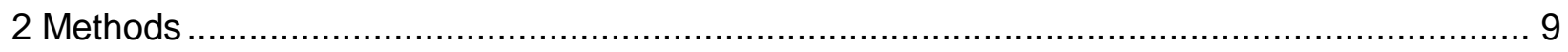

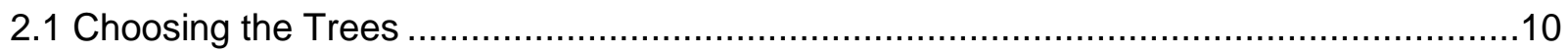

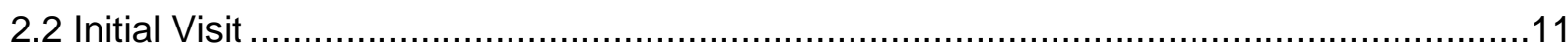

2.3 Collecting the Data at Each Visit................................................................................

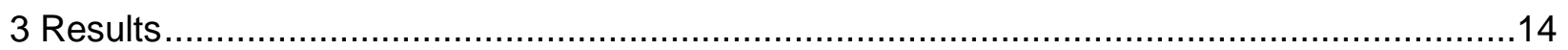

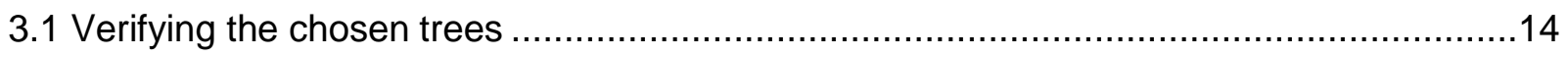

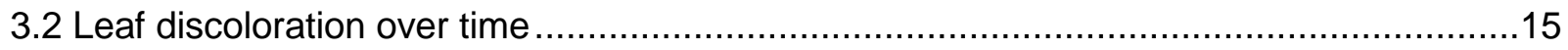

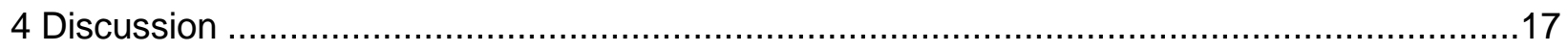

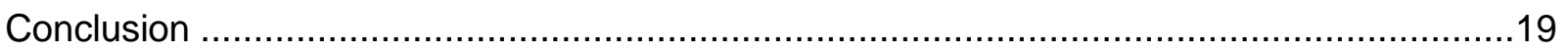

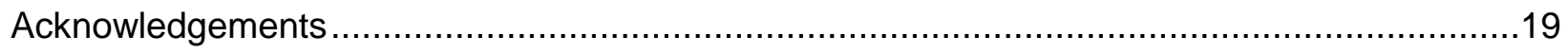

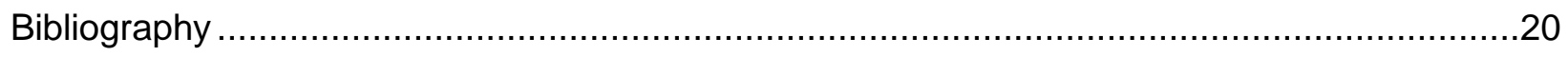




\section{Abstract}

Due to the heterogeneity of the urban heat island, we can think of the variable influence of urbanization on air temperature as more of an urban heat mosaic. Climate change has caused a resurgence of interest in the way temperature affects how organisms, such as street trees, undergo cyclic changes in their life cycle. Such changes include budburst or, less commonly, timing of senescence. Little is known about how the urban heat mosaic could be affecting the phenology of different urban trees. Because street trees are one of the more prominent ecosystem engineers of the urban landscape, variable influences of temperature on tree phenology could impact urban ecosystem ecology and human health. This study investigated the timing of senescence for Acer macrophyllum (Bigleaf maple) and Acer platanoides (Norway maple) in warm and cool zones in Portland, Oregon. Senescence was characterized as the changing of leaf color, and a total of thirty-two trees were observed over the course of October and November to track senescence. These observations showed a significantly late senescence time of about three days for Norway maples in warm zones $(p=$ 0.13 ). Though it was hypothesized that the cool zones would senesce sooner than the warm zones, this was only the case for Norway maples, as Bigleaf maples had cool zones senesce about two days later than the warm zones $(p=0.14)$. This differential response may be explained by an increased vulnerability of Bigleaf maple to urbanization and heat in general. More research is needed to understand how different street tree species respond to variation in environmental conditions and respective socioecological implications.

\section{Introduction}

Variation within the urban heat island $(\mathrm{UHI})$ is extremely common and matches the characteristics that Pickett and Cadenasso talk about in their 2007 paper describing the urban landscape as a mosaic, specifically when concerned with vegetation. This mosaic-like ecosystem is different throughout every city, but most have areas of gray infrastructure and other contributing factors leading to warm zones within the UHI. The authors profess a need to understand this ecosystem like any other. In the following review, I will first discuss the structure of the $\mathrm{UHI}$, and how it is created, followed by a brief mention of its function and impact on tree phenology in Acer macrophyllum (Bigleaf maple) and Acer platanoides (Norway maple).

\subsection{Causes of the Urban Heat Island}

The Urban Heat Island effect (UHI) is the product of gray and black top infrastructure paired with deforestation to result in a general temperature rise in urban areas (Rizwan et al., 2008). It is a driver of local climate change but has the distinction of being able to be easily 
mitigated (Susca et. al., 2011). Urbanization has caused increases in the amount of impervious surface and decreases in the arboreal canopy and overall vegetation (Hart, 2008). This creates a temperature difference throughout the urban to rural gradient (Makido, 2016). The UHI has even been correlated to community health risks that could be eased through the increase of green spaces (Feng et al., 2017; Shandas, 2009), including shade trees such as Bigleaf maples. Significant controllable variables also contribute to the UHI, such as anthropogenic heat. This includes heat from transportation (planes, trains, and cars) as well as heat caused by industrial output, and building air conditioning units (Rizwan et al., 2008).

Though it is hard to pinpoint every cause of $\mathrm{UHI}$, there are clear correlations between vegetation increases and temperature decreases within the urban center. Planting trees is specifically an effective and supported way to decrease the UHI (Basset et al., 2010) and so by studying the impact of different temperature zones (warm versus cool) within the UHI on their physiology, measures can be taken to improve their overall health. There is a prevalent need to further study the UHI, and improve its protocols (Oke, 2009) in order to better the understanding and access to how the urban heat island is impacting ecosystems, and how to mitigate it. This

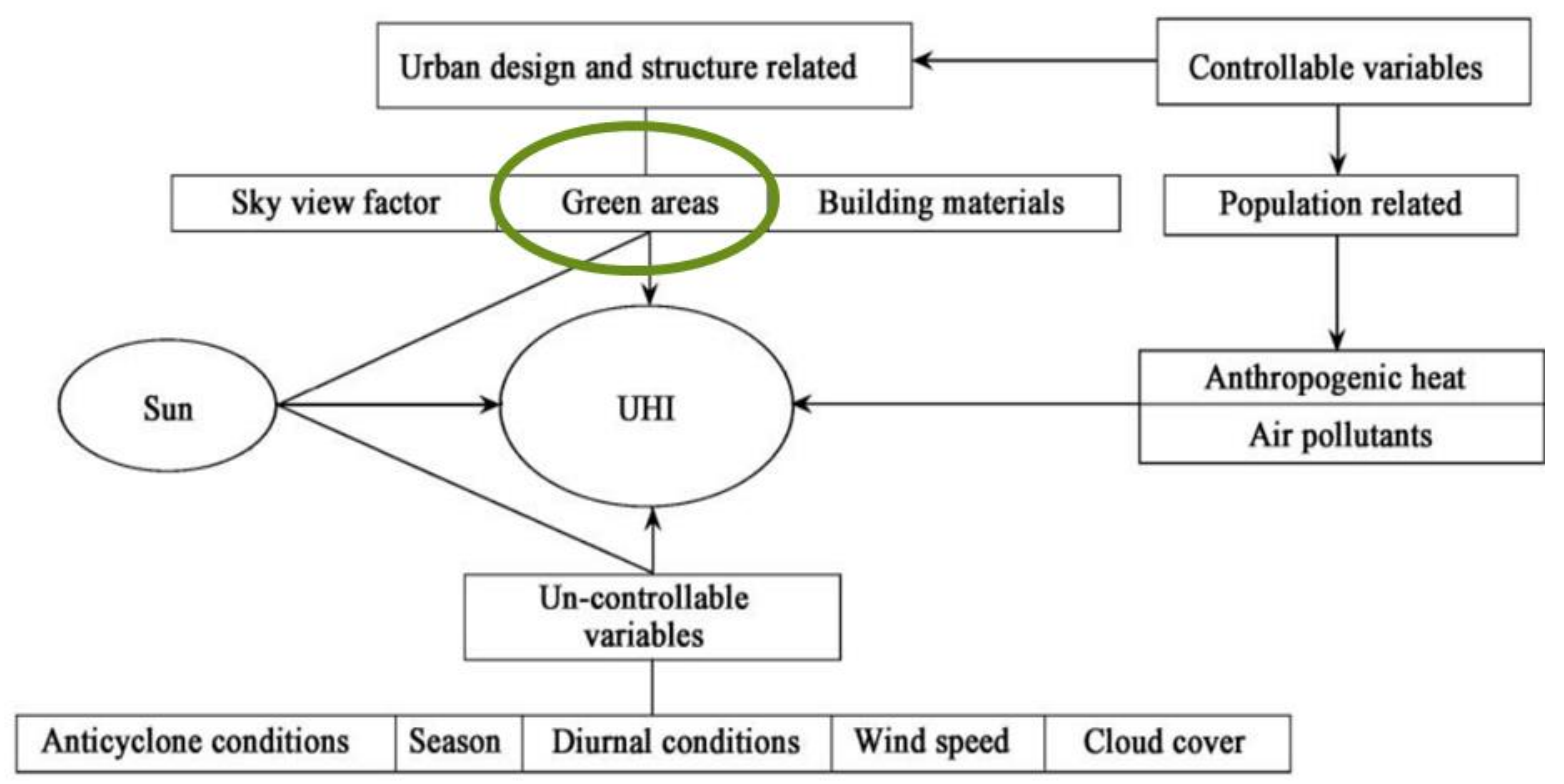

Figure 1: The source of the urban heat island and the factors that support it (Rizwan et al., 2008) 
mitigation is typically green spaces, however, trees and other vegetation are impacted by heat and further investigation is needed to assess the viability of this mitigation technique in regards to long-term ecosystem health.

\subsection{Mitigation of the UHI}

As mentioned above, popular mitigation of these warm zones is increased vegetation and canopy. This increase in canopy actively absorbs the heat radiated by the sun, and instead of releasing it, much like gray infrastructure would, it turns it into bioavailable energy known as glucose (Rizwan et al., 2008). The physiological structures that actively turn this energy into glucose, along with water and carbon dioxide, are chlorophyll, which resides primarily in the leaves. These leaves make up the canopy, and the canopy goes into a dormancy stage called senescence every autumn. The study of all the stages of the tree's life cycle is called phenology, and is an important function dictated by the environmental structure surrounding and individual organism. Understanding how growing seasons change in response to urban heat could impact the timing of these canopies, and therefor potential mitigation of the UHI.

Mitigation can also come in the form of different building materials, such as alternative concretes and pavements (Haselbach, 2009), and less light absorbing materials (Rizwan et al., 2008). Green roofs are among one of the mitigation techniques involving increased vegetation, and have been shown to decrease UHI effects in urban centers (Li et al., 2014). Studies done looking at increased vegetation independent of green roofs also shows about a 1.4-degree Fahrenheit decrease of urban centers (Yun et al., 2013). With a multitude of ways to mitigate the UHI, focusing on trees as the majority of the urban canopy could help inform future planning in mitigation techniques. 


\subsection{Impacts the UHI has on Vegetation and the Ecosystem}

Increased temperatures impact the physiology of trees in several ways, as well as the phenology (Slaney, 2007). These increases have also negatively impact tree vasculature (Ramirez, 2019), by lowering the efficiency of the phloem. Water transport was significantly slower at warmer temperatures than at standard temperatures. With an increase in impermeable surfaces, the urban landscape also causes a decrease in available water. This is compounded by the temperature increase from the UHI and can cause water stress to impact tree health. These associated detriments to tree health caused by the UHI and urbanization in general could have impacts on the tree's phenology as well as its health, which could further harm its overall fitness as it relates to reproduction and life cycles in general.

The UHI also has significant risks to public health, where studies have correlated warmer areas of an UHI correlating to increased development of asthma in adolescents (Feng and Astel-Burt, 2017). Heat stroke is another impact on health to be aware of in communities that fall into the warmer portion of the urban landscape (Shandas, 2009). Its risks extend to other portions of the urban ecosystem, including having significant warming effects on bodies of water, which can cause harmful environments for aquatic life (Guhathakurta and Gober, 2007). Mitigation of the UHI could lead to an overall healthier ecosystem. 


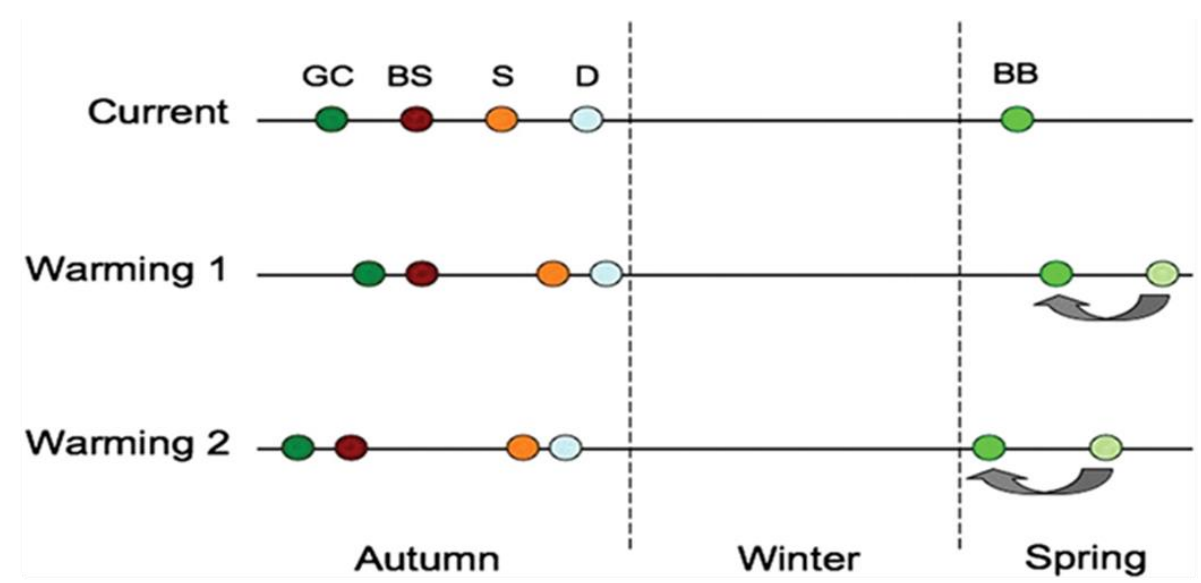

Figure 2. Potential changes in phenological events under current and elevated temperature climates

Tree Physiology, Volume 31, Issue 5, May 2011, Pages 469-471, https://doi.org/10.1093/treephys/tpro44 OXFORD

Figure 2. Potential changes in phenological events under current and elevated temperature climates. Growth cessation (GC), bud set (BS), senescence (S) and dormancy (D) must occur sequentially before winter; after chilling requirements are met in the winter, bud burst (BB) occurs in the spring (Current). In the Warming 1 scenario, elevated temperatures delay growth cessation (Rohde et al. 2011), reduce the time required for bud set, extend the duration of leaf senescence and hasten the onset of dormancy. Deeper winter dormancy and later dormancy onset delay bud burst in the spring compared with the Current scenario (pale green circle), but warmer spring temperatures encourage earlier bud burst (gray arrow), resulting in a slight delay in actual bud burst (bright green circle) compared with Current conditions. In the Warming 2 scenario, warmer temperatures accelerate growth cessation (Kalcsits et al. 2009), hasten bud set, slow senescence even more and greatly hasten dormancy development. Although the deeper winter dormancy induced in this scenario should also delay spring bud burst, warmer spring temperatures again encourage earlier bud burst, resulting in earlier than current bud burst in the tree. Many such scenarios can be arrived at by altering the time periods between phenological events, thus allowing large-scale signs of phenology shifts, such as leaf senescence and bud burst, to be delayed or hastened.

Unless provided in the caption above, the following copyright applies to the content of this slide: @ Daniel Way, 2011. Published by Oxford University Press. All rights reserved.

\subsection{Tree Phenology and Senescence}

Phenology is the general study of the life cycle of an organism and includes stages such

as budburst and leaf senescence. Though nutrient and water transport are vital for the life of the

tree, the phenological impact of budburst and senescence is also quite significant. Budburst

changes can impact insect populations (Hunter, 1992) and pollination patterns, decreasing

reproduction among non-local populations of the same species, decreasing genetic diversity.

Temperature is a known effector of early budburst (Van den Berg, 1987), and therefore can be

managed to prevent this.

Tree senescence is on the other temporal end of this process, indicating the beginning

of dormancy for the tree, or a drop in leaves to conserve nutrients and energy. It impacts the 
timing of budburst and significantly plays into the other steps in the tree's life cycle (Figure 2; Way, 2011). The timing of these cycles is crucial to avoiding physical harm from harsh winter temperatures (Way, 2011) and the aforementioned impact on invertebrate communities and general reproductive health of the organism. This has been measured by most researchers up to this point by tracking 50\% leaf drop according to a meta-analysis done by Gill et al. in 2015 . Late senescence can impact ecosystem carbon balance and can have other harmful effects on the ecosystem (Fu et al., 2014). With an extended growing period, due to early budburst and late senescence, more data needs to be collected to see what possible implications an extended growing period could have on soil carbon stores, timing of canopy exposure, tree health, and overall ecosystem health (Fu et al., 2014).

\subsection{A Response to the Declining Health of the Urban Ecosystem}

The goal of this study is to learn more about the UHI and how this localized climate change impacts deciduous tree phenological stages, specifically senescence. Two species in the Acer family that are common in Portland will be monitored as indicators for late senescence within different temperature zones in the UHI. Knowing more about phenological stages can help facilitate better genetic diversity among these urban ecosystems and give data that could be pertinent to biotic pollination, such as timing, and discrepancies between environmental cues and phenological stage (Hunter, 1992). Decreasing the overall heat island will also improve community health of both the ecosystem, and the people living there (Shandas, 2009).

Sustainable urbanization is going to be one of the keys to mitigating warming and emissions in the future. UHI is a way to look at climate change in localized spots and see what impacts it has on the ecosystems of the urban setting. By researching common Acer species response to this local warming, policy can be made to implement infrastructures such as buffer zones, to protect tree phenology stages, and in turn pollinator timelines and response to those stages. With pollinator populations declining, and increased gray infrastructure causing abiotic 
pollination pathways to not be as efficient, maintaining these pollinator timelines is crucial for ecosystem health. By starting in the urban centers, new conservation policy backed by this and similar research might be able to become standard management practice.

To test the relationship between temperature zone within the $\mathrm{UHI}$, and the phenological stages of senescence in Acer platanoides (Norway maple, non-native) and Acer macrophyllum (big leaf maple, native) in hot and cold areas in Portland as established by Dr. Shandas and the SUPR Lab (Shandas et al., 2019) the following methods will be used. These methods will help answer the following question: Does the temperature variation in the UHI cause a variation in autumnal senescence as measured by leaf discoloration in Bigleaf and Norway maples in Portland? It is hypothesized that increased temperature causes senescence to happen later, specifically in European beech trees (Fu et al., 2018). It is expected that this will be the pattern found in these Acer species, but a gap in literature leaves a need for this research.

\section{Methods}

To find an optimum sample set to study a species map provided by the City of Portland Parks and Recreation Department, and heat profile map of Portland, provided by Dr. Vivek Shandas (PSU College of Urban Planning) were used (figure 1). The optimum sample set consists of an even distribution of native and non-native species among an even distribution of city hotspots and cold spots throughout the urban heat island of Portland, OR. There were 6-8 individuals for the hotspot locations and 6-8 for the cold spot locations (GLOBE, 2005). Individual street tree selection will be done prior to leaf fall to allow for ease of identification, to be able to discern between Norway maples, and big leaf maples (Gazal, 2008).

The current literature has various protocols for measuring budburst (GLOBE, 2005), and is incomplete, and so the consolidation of this information is needed. Protocols for senescence are even less established, so much work currently needs to be done to explore measuring and analyzing senescence, and eventually creating a universal protocol. This would increase the 
ability for this information to be collected by citizens and create a protocol that could be used for general use within citizen science. Creating a solid database for budburst and senescence times throughout Portland would also be a big step forward in supporting future research. Using citizen science and making data more abundant and accessible for scientists around the world is a crucial part in cultivating change. This will not only increase education opportunities and awareness of urbanizations impact on the environment but will also create data to be used in novel ways for other studies involving tree phenology and its relation to temperature.

\subsection{Choosing the Trees}

Choosing the trees and the sites of study using the database collected in the tree inventory project done by the City of Portland Parks and Recreation Department allowed for a variety of confounding variables to be taken into consideration. These GIS layers showed a strong presence of both Norway and Bigleaf maples, demonstrating that these trees make up a great deal of the urban canopy of Portland. Bigleaf maples are also a heritage tree in Portland (Shandas, 2019) and looking at how it responds to urban stress in comparison to its non-native counterpart, the Norway maple, could allow for further investigation into native and non-native interactions in the future. For these reasons, Bigleaf and Norway maples were chosen as the species of interest. The database had DBH (diameter at breast height), tree condition, and pit width among other variables recorded on it, allowing for a general screening of specific trees. Trees recorded to be in poor health, or outside of the DBH parameter of $35 \mathrm{~cm}-60 \mathrm{~cm}$ were not considered, along with trees that had a pit width smaller than 2 feet. These variables were considered to control for age, and possible constriction of nutrient availability, including a history of poor health. Once the trees were chosen on the tree inventory database, the SUPR lab's heat map was consulted to place it in a temperature zone, according to its measure of temperature throughout the day, with peak temperature being the primary consideration. 


\subsection{Initial Visit}

To verify and add to these variables, the initial visit included a measure of the tree height with a clinometer, a verification of the $\mathrm{DBH}$ using a DBH measuring tape, and an overview of pit width and the density of the canopy and understory. Onset HOBO MX2201 temperature logger pendants (Bourne, Massachusetts, USA) were also used to collect temperature data of the ambient air temperature at the site to bolster the information provided by the SUPR lab. Soil moisture was also collected here using an AMS soil core sampler (American Falls, Idaho, USA) and a drying oven to determine the water content percentage by mass. After these initial visits,

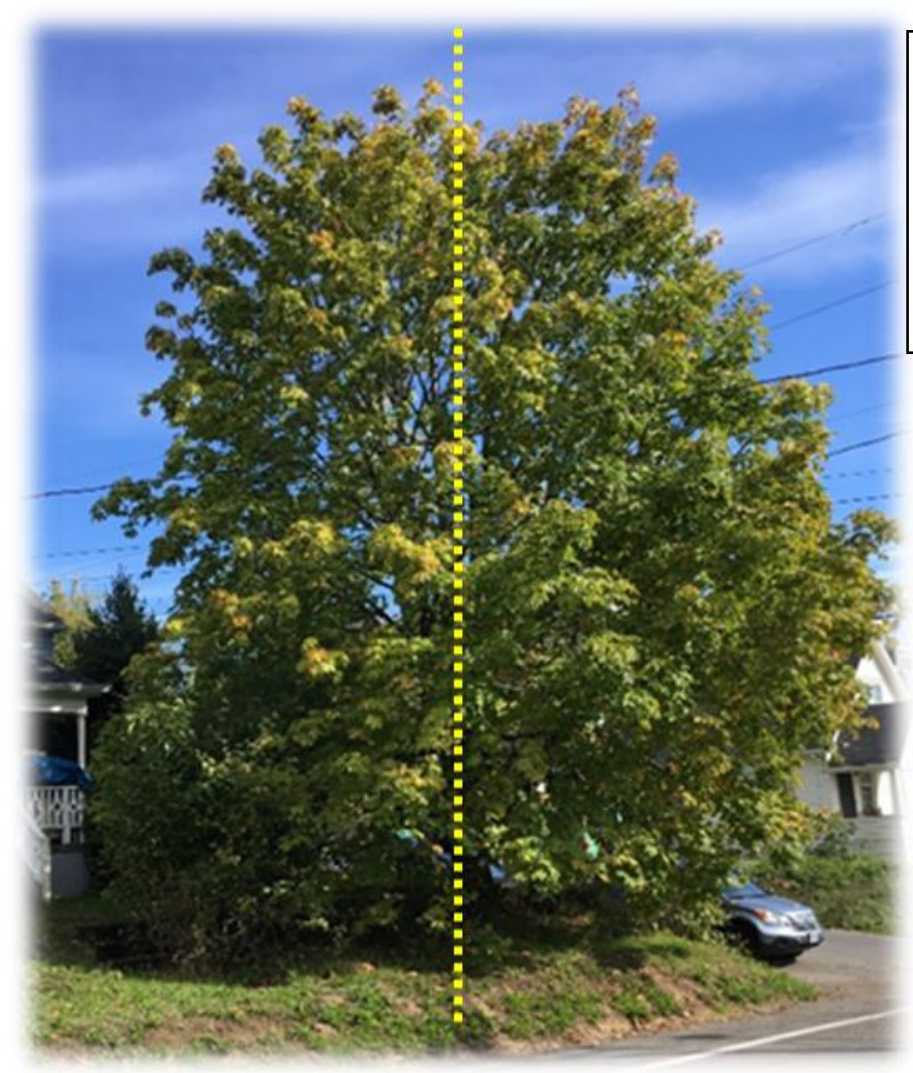

Figure 3: Visualization of how the percentage of leaves was determined. Each side of the line is a hemisphere, either the north or south hemisphere. They were observed in their entirety to get a percentage of leaf fall and leaf discoloration for each hemisphere, which was then averaged out to get a percentage for entire tree. 
each site was revisited roughly every other week, with a minimum of three collections total throughout the months of October and November.
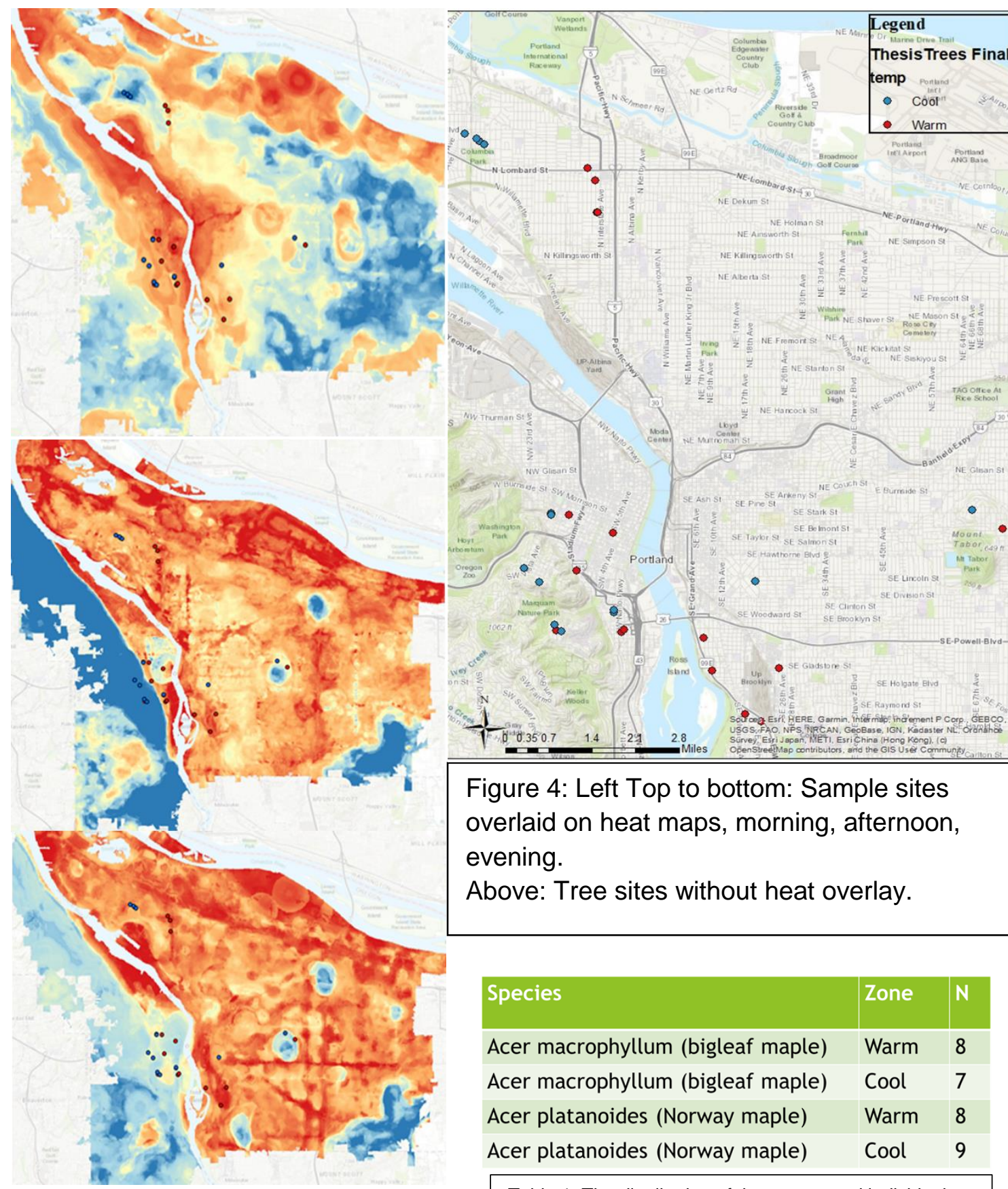

Figure 4: Left Top to bottom: Sample sites overlaid on heat maps, morning, afternoon, evening.

Above: Tree sites without heat overlay.

\begin{tabular}{|c|c|c|}
\hline Species & Zone & N \\
\hline Acer macrophyllum (bigleaf maple) & Warm & 8 \\
\hline Acer macrophyllum (bigleaf maple) & Cool & 7 \\
\hline Acer platanoides (Norway maple) & Warm & 8 \\
\hline Acer platanoides (Norway maple) & Cool & 9 \\
\hline
\end{tabular}




\subsection{Collecting the Data at Each Visit}

Three individuals were responsible for recording data, and on 10/13/2019 and $10 / 14 / 2019$, went out as a group in order to calibrate one another on collecting percentages, as to best record the data accurately. This negated some of the variation via bias in the end results. The 38 individual trees were distributed among the observers who visited the trees to collect the data on a pre-determined schedule.

At these visits leaf fall and leaf discoloration were recorded in percentages of the total tree. This was done by splitting the tree into two hemispheres, one as the south face, and the other as the north face (figure 3). A rough estimation of each hemisphere was recorded and averaged to get a total percentage for the tree overall. Leaf senescence was defined as greater than or equal to $75 \%$ leaf discoloration for an individual leaf. This was done because the degradation of chlorophyll $A$ and $B$ is what causes the discoloration, and is driven by the physiological response of senescence, whereas leaf fall can be exacerbated by weather or other environmental factors, causing a possible misrepresentation of actual senescence. The sites were visited every other week, staggered so there was an observation every week, but at a different site. During observations, the tree was assessed for leaf discoloration, and leaf fall.

To analyze these data, t-tests showing if there was a significant difference in rate of senescence amongst the varying groups were created in excel. The various groups were divided up into species of tree ( $A$. macrophyllum and $A$. platanoides are ACMA and ACPL respectively) and zone, which was either warm or cool. Analysis of variance (ANOVA) was used to identify the individuals studied, and to identify what environmental factors were significantly different among the four groups studied (table 2). The placement of the trees in warm or cool zones was included in this ANOVA as well to validate the placement based on the heat maps in figure 4 . 


\section{Results}

\subsection{Verifying the chosen trees}

The trees chosen were verified to be significantly similar regarding height of the tree and diameter at breast height but showed significant difference in soil moisture content between the warm and cool zones (table 2). The temperature probe data showed about a 2-degree difference (Fahrenheit) in mean daily temperature readings on average for both species between temperature zones. A p-value of .0059 showed a strong significant difference between the temperatures for Bigleaf maples but had a relatively high $p$-value of .13 for Norway maples. The amount of temperature data $(n=2)$ recovered from the Norway maples warm zones was significantly less than the Bigleaf maples warm zones $(n=4)$, so the data for the Norway maples has less credibility. The cool zones for Bigleaf $(n=6)$ and Norway $(n=5)$ maples had 3 and 2 more sites representing their cool zones than the warm, respectively. When both the placement based off of the UHI maps and the temperature probes, the sites represented their respective zones appropriately, giving an accurate depiction of what warm and cool might do to the phenology of the trees. 


\begin{tabular}{|l|l|l|l|l|l|l|}
\hline & $\begin{array}{l}\text { Bigleaf } \\
\text { Hot }\end{array}$ & $\begin{array}{l}\text { Bigleaf } \\
\text { Cold }\end{array}$ & Norway Hot & $\begin{array}{l}\text { Norway } \\
\text { Cold }\end{array}$ & \multicolumn{2}{|l|}{$\begin{array}{l}\text { P value Between warm } \\
\text { and cool zones }\end{array}$} \\
\cline { 5 - 7 } & & & & Bigleaf & Norway \\
\hline $\begin{array}{l}\text { Average } \\
\text { Temp (F) }\end{array}$ & 49.62382 & 47.44931 & 48.59777 & 46.71596 & .0059 & .13 \\
\hline $\begin{array}{l}\text { Soil } \\
\text { Moisture }\end{array}$ & $13 \%$ & $19 \%$ & $15 \%$ & $18 \%$ & .01 & .16 \\
\hline $\begin{array}{l}\text { Tree } \\
\text { Height } \\
(\mathrm{m})\end{array}$ & 13.76 & 20.54 & 13.89 & 12.26 & .53 & \\
\hline $\begin{array}{l}\mathrm{DBH} \\
(\mathrm{cm})\end{array}$ & 58.36 & 57.96 & 47.61 & 54.87 & .36 & \\
\hline
\end{tabular}

Table 2: Averages, and p-values of the difference between groups for tree height, diameter at breast height, and soil moisture.

\subsection{Leaf discoloration over time}

Though leaf fall data was collected, this was not used in this study. The percentage of leaves discolored was used to represent senescence and degradation of chlorophyll. The average discoloration of the leaves on the entire tree were put into a bar graph to demonstrate how far a group has senesced (figure 4). These averages were for the dates pertaining most to senescence which was October $13^{\text {th }}$ to November $11^{\text {th }}$. Norway maple had an average percentage of leaves discolored of $55 \%$ for the warm zones, and $76 \%$ for the cool zones. This showed that the cool zones were $21 \%$ more senesced than the warm zones. A t-test was ran and a p-value of .13 was found between these two groups at an alpha level of .15.

Bigleaf maple was found to have an average of $86 \%$ leaves discolored in the warm zones and $76 \%$ in the cool zones, putting the number of leaves senesced during this timeframe $10 \%$ higher in the warm zones. At the same alpha level of .15 a significant difference was found with a $p$-value of .14 found. 
The complete data set is demonstrated on the scatter plots in figure 4, with vertical bars indicating the time period further analyzed to calculate the averages used to represent the data in the bar graph. This was done to minimize the analysis during the time of $100 \%$ discoloration and $0 \%$ discoloration.
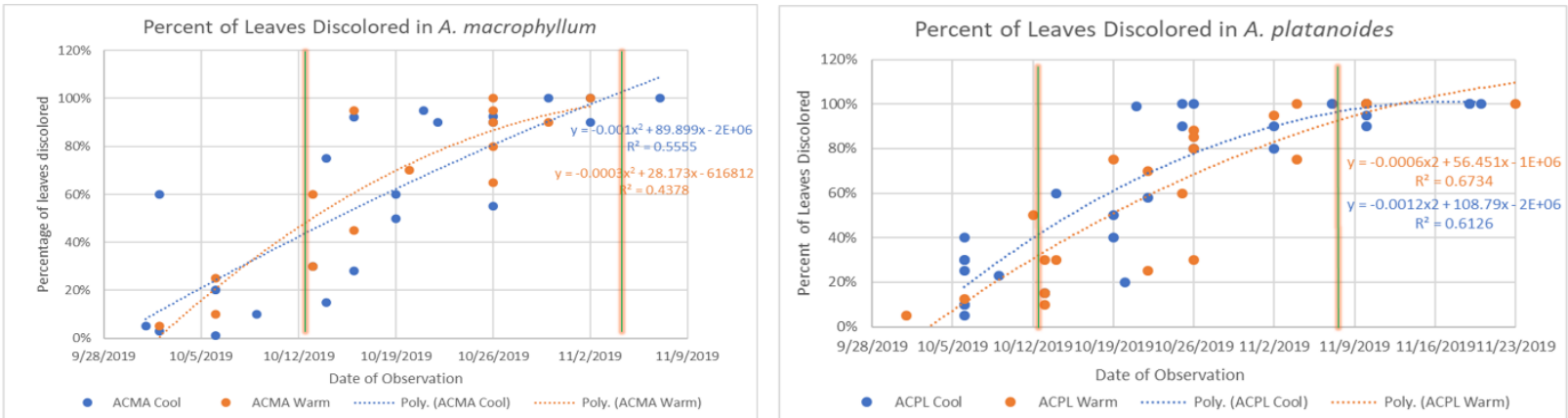

Figure 5: Scatterplots showing the percent of leaves discolored over the total span of the data collection period. Vertical bars represent the timeframe further analyzed in figure 6.

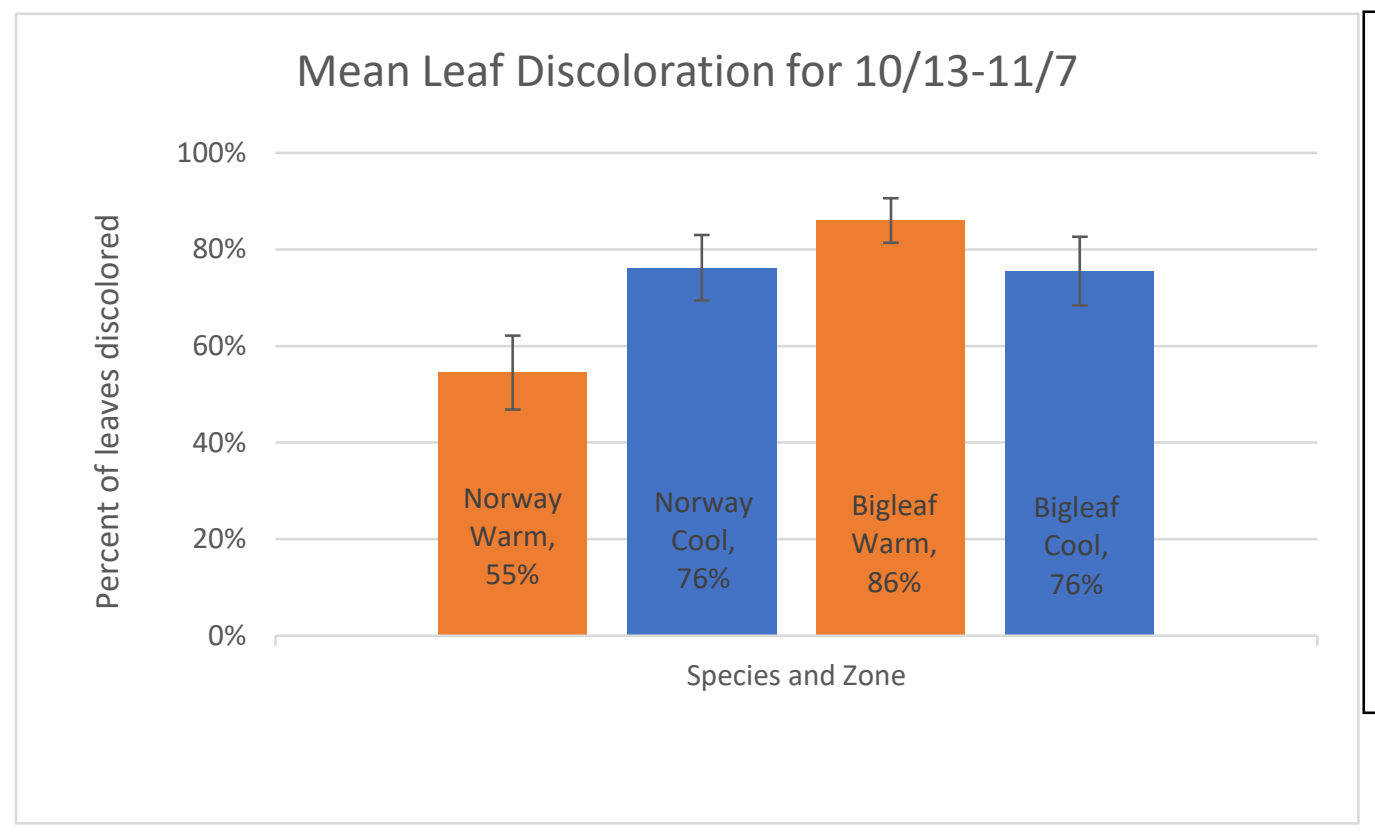

Figure 6: A bar graph of the mean leaf discoloration for the portion of time that represents when the majority of trees were going through senescence. A clear significant difference can be seen between Acer platanoides (ACPL, Norway maple), with a larger percentage of leaves being discolored in the cool zones during this snpashot of time. Acer macrophyllum (ACMA, Bigleaf maple) showed a smaller difference in the opposite direction, with a larger percentage of leaves being discolored in the warm zones. 


\section{Discussion}

Our findings support the hypothesized outcome for only one of the two species. Norway maples showed a significantly late senescence in warm zones compared to cool zones. However, Bigleaf maple supported the opposite outcome by experiencing earlier senescence in warm zones as opposed to cool zones. Bigleaf maples are the native tree, while Norway maples were introduced as a non-native and have been doing very well in Portland. When compared, there are many more Norway maples in the city (City of Portland street tree project, 2014). The city has also stopped maintaining and planting maple trees in Portland due to their prevalence as a street tree. Factors such as this, as well as researchers studying leafhoppers (Empoasca elongata), a potential invertebrate parasite of Bigleaf maples, could support that Bigleaf maples are declining in health (Willhite, 2020). These parasites have led to induced senescence in Bigleaf maples being studied on the coast by the U.S. Forest Service (Willhite, 2020).

This decline in health could be considered an alternative hypothesis producing the results above. However, this is still unknown. The total physiological response of Bigleaf maples to increased temperature should be studied in the future. Investigating if there is a correlation between poorer health and higher temperatures in Bigleaf maples would establish the need to study the physiological impacts of temperature on the native Bigleaf and other species.

In this study leaf discoloration was chosen over leaf fall to represent senescence even though leaf fall was used more in other studies according to the meta-analysis done in 2015 by Gill et al. This practice should be considered for future studies on senescence because chlorophyll degradation is the functional way most plants reallocate their nutrients for dormancy. Leaf fall could be influenced by outside environmental and mechanical factors, so leaf discoloration should be significantly considered to represent senescence. However, leaf fall can provide valuable information about how the environment is impacting the tree, and should be considered for inspecting other variables 
Other possible reasons for an appearance of vulnerability of urban trees could be due to photoperiods impact from the red and extra red light from street lamps causing later senescence. Soil moisture could also be an influencer of senescence in Bigleaf maples (Willhite, 2020), and could have varying influences on urban trees in general. If native species are drought sensitive and respond with early senescence, and non-natives are not as drought sensitive, then soil moisture would appear to correlate to our results. Researching species to see to what extent they are drought sensitive could help infer how they should be managed.

One way to do that could be increasing the amount of citizen science projects done concerning tree phenology. Creating succinct protocols for a general public would increase the ability for this information to be collected by concerned citizens and allow for a database to be created. Creating a solid database for budburst and senescence times throughout Portland would also be a big step forward in supporting future research. Using citizen science and making data more abundant and accessible for scientists around the world is a crucial part in cultivating change. This will not only increase education opportunities and awareness of urbanizations impact on the environment but will also create data to be used in novel ways for other studies involving tree phenology and its relation to temperature.

There are many gaps in research concerning the general physiology and phenology of these urban ecosystem engineers, let alone temperature's influence on them. This being said, it has been established that ecologists and urban planners must work together to create urban landscapes conscious of the socioeconomic, cultural, and environmental needs (Felson and Pickett, 2005). Though there has been a clear increase in the collaboration between these disciplines in recent decades by groups such as the Sustaining Urban Places (SUPR lab, Portland State University) and Urban Ecology Design (UEDLAB, Yale University) labs, more longitudinal research needs to be conducted in controlled environments on urban species to apply to better planning practices when it comes to ecosystem engineers such as heritage trees. 


\section{Conclusion}

Based on the findings that Norway maples senesced as expected, and Bigleaf maples senesced in the opposite manner, it is important to recognize that this variability in the UHI may have variable impacts on a variety of species making up the urban landscape. These findings support the need for more research in learning how these vital ecosystem engineers' function within the structure of the UHI so that we may learn how to improve and normalize their responses to the impact urbanization has on their health. Being able to improve the health of these creators of the canopy, and therefore increase beneficial cool zones, could help us decrease both the amount of public health risk factors and ecosystem health risk factors created by the UHI. This improvement to ecosystem health would be a first step towards creating a more sustainable habitat for future generations.

\section{Acknowledgements}

I would first like to thank Olyssa Starry for all her support as a mentor and advisor for not only this project, but the last three years here at PSU. Amelia Drake, an EXITO scholar, gave significant support in collecting and organizing data for this project, and for that, I thank you. Special thanks to Dr. Vivek Shandas for his contributions to the idea and content of this study. I would also like to thank Portland Parks and Rec Urban Forestry for their help with permitting the trees and providing the Street Trees layer. Randy Morris also provided valuable help with creating the maps. Valuable feedback and information was given by many at the Urban Ecosystem Research Consortium including Rick Zenn and Lori Hennings, thank you. To all others who provided support and feedback on this project, thank you! 


\section{Bibliography}

Basset, E., \& Shandas, V. (2010). Innovation and climate action planning. Perspectives from municipal plans. Journal of the American Planning Association, 76(4), 435-450.

Felson, A. J., \& Pickett, S. T. (2005). Designed experiments: new approaches to studying urban ecosystems. Frontiers in Ecology and the Environment, 3(10), 549-556.

Feng, X., \& Astell-Burt, T. (2017). Is neighborhood green space protective against associations between child asthma, neighborhood traffic volume and perceived lack of area safety? Multilevel analysis of 4447 Australian children. International journal of environmental research and public health, 14(5), 543.

Fu, Y. H., Piao, S., Delpierre, N., Hao, F., Hänninen, H., Liu, Y., ... \& Campioli, M. (2018). Larger temperature response of autumn leaf senescence than spring leaf-out phenology. Global change biology, 24(5), 2159-2168. 
Fu, Y. S., Campioli, M., Vitasse, Y., De Boeck, H. J., Van den Berge, J., AbdElgawad, H., ... \& Janssens, I. A. (2014). Variation in leaf flushing date influences autumnal senescence and next year's flushing date in two temperate tree species. Proceedings of the National Academy of Sciences, 111(20), 7355-7360.

Gazal, R., White, M. A., Gillies, R., Rodemaker, E. L. I., Sparrow, E., \& Gordon, L. (2008). GLOBE students, teachers, and scientists demonstrate variable differences between urban and rural leaf phenology. Global Change Biology, 14(7), 1568-1580.

Gill, A. L., Gallinat, A. S., Sanders-DeMott, R., Rigden, A. J., Short Gianotti, D. J., Mantooth, J. A., \& Templer, P. H. (2015). Changes in autumn senescence in northern hemisphere deciduous trees: a metaanalysis of autumn phenology studies. Annals of Botany, 116(6), 875-888.

G. (2005). GLOBE Budburst Protocol. Retrieved March 4, 2019, from https://www.globe.gov/documents/356823/2538681/earth prot budburst.pdf

Guhathakurta, S., \& Gober, P. (2007). The impact of the Phoenix urban heat island on residential water use. Journal of the American Planning Association, 73(3), 317-329.

Hart, M. A., \& Sailor, D. J. (2009). Quantifying the influence of land-use and surface characteristics on spatial variability in the urban heat island. Theoretical and applied climatology, 95(3-4), 397-406.

Haselbach, L. (2009). Pervious concrete and mitigation of the urban heat island effect (No. 09-0098).

Hunter, M. D. (1992). A variable insect-plant interaction: the relationship between tree budburst phenology and population levels of insect herbivores among trees. Ecological Entomology, 17(1), 91-95.

Li, D., Bou-Zeid, E., \& Oppenheimer, M. (2014). The effectiveness of cool and green roofs as urban heat island mitigation strategies. Environmental Research Letters, 9(5), 055002. 
Makido, Y., Shandas, V., Ferwati, S., \& Sailor, D. (2016). Daytime variation of urban heat islands: the case study of Doha, Qatar. Climate, 4(2), 32.

Manley G. (1958), On the frequency of snow fall in metropolitan England. Quart J Roy Meteor Soc ; 84 (359):70-72.

Noodén, L. D. (Ed.). (2012). Senescence and aging in plants. Elsevier.

Oke, T. R. (2009, June). The need to establish protocols in urban heat island work. In The seventh International Conference on Urban Climate (Vol. 29).

Pickett, S. T., \& Cadenasso, M. L. (2008). Linking ecological and built components of urban mosaics: an open cycle of ecological design. Journal of Ecology, 8-12.

Rizwan, A. M., Dennis, L. Y., \& Chunho, L. I. U. (2008). A review on the generation, determination and mitigation of Urban Heat Island. Journal of Environmental Sciences, 20(1), 120-128.

Shandas, V. (2009). Climate justice: Towards a proactive response to social inequities. Connections.

Shandas, V., Gall, E., George, L., \& Messer, L. (2019). SUSTAINING URBAN PLACES RESEARCH LAB. Retrieved from https://climatecope.research.pdx.edu/

Slaney, M., Wallin, G., Medhurst, J., \& Linder, S. (2007). Impact of elevated carbon dioxide concentration and temperature on bud burst and shoot growth of boreal Norway spruce. Tree Physiology, 27(2), 301312. 
Susca, T., Gaffin, S. R., \& Dell'Osso, G. R. (2011). Positive effects of vegetation: Urban heat island and green roofs. Environmental pollution, 159(8-9), 2119-2126.

Van den Berg, G. A. (1987). Influence of temperature on bud break, shoot growth, flower bud atrophy and winter production of glasshouse roses, 17-28.

Vegis, A. (1963). Climatic control of germination, bud break, and dormancy. Environmental control of plant growth, 265-287.

Way, D. A. (2011). Tree phenology responses to warming: spring forward, fall back?. Tree physiology, 31(5), 469-471.

Willhite, B. (2020). Declining Bigleaf Maples in Oregon: What's Going On? [PowerPoint slides]. Retrieved from

https://www.forestry.oregonstate.edu/sites/default/files/Willhite Declining\%20Bigleaf\%20Maples SOS\%2 $\underline{02020 . p d f}$

Yun, H. C., Kim, M. G., \& Jung, K. Y. (2013). Analysis of temperature change by forest growth for mitigation of the urban heat island. Journal of the Korean Society of Surveying, Geodesy, Photogrammetry and Cartography, 31(2), 143-150. 